rung zu der proklamierten Höhenkunst vorgestellt wird. Vgl. auch Fritz Schlawe, „,Literarische Zeitschriften 1885-1910" (Sammlung Metzler), 1961, S. 80.

1 Vgl. die vierte Strophe des „Künstler-Liedes" aus „Wilhelm Meisters Wanderjahre", Zweites Buch, achtes Kapitel. In Vers 3 hier fälschlich „,Kunstgebilde“ statt „Kunstgefilde“.

2 Aus dem Gespräch mit Eckermann vom 11. März 1832.

\title{
84 JOHANNES JÖRGENSEN »VON DER KUNST«
}

Aus: »Gottesminne«, Jg 1, 1903, H. 3, S. 116.

Das Ziel der Kunst ist die Verwirklichung der Idee, die Darstellung der Dinge, wie sie an sich, u. mit den Augen Gottes gesehen, sind. Des Künstlers Aufgabe ist es, die durch die Sünde zerstörte Einheit wiederherzustellen - jene ursprüngliche Einheit des Guten und des Schönen, welche die Wahrheit ist. Nur so ist die Kunst wahr. Die wahre Kunst ist die wahrhaftige Kunst, welche die himmlische Schönheit der Tugend und die höllische Hässlichkeit der Sünde den Menschen einleuchten lässt. Die wahre Kunst ist die Offenbarung des wahren Karakters der Dinge, die Offenbarung des Wesens, nicht des Scheines. Die Moralität ist daher das Organ aller grossen Kunst, von den Griechen bis Dante, von Dante bis Shakespeare und allen neueren und neuesten wahren Künstlern. Wem dieses Organ fehlt, kann das Dasein nach seiner innersten Realität nicht fassen, seine Kunst wird daher keine wirklichkeitstreue, sondern im tiefsten Grunde eine unwahre, falsche, somit schädliche sein. Mag sie in aller äusserer Pracht einherschreiten, ihr Kern ist Lüge, und sie ist zur Menschennahrung nimmer dienlich, denn das Brot des Menschen ist die Wahrheit.

Nur die Wirklichkeit, die wahre Wirklichkeit, ist der Gegenstand der Kunst, der wahren Kunst. Aber nur der von Gott erleuchtete Geist sieht die Wirklichkeit. Gott ist somit das eigentliche Medium des künstlerischen Schaffens; nur in Gott und durch Gott sieht der Künstler die Wahrheit, welche die wirkliche Schönheit ist. Nur dem gottliebenden Auge ist der Himmel der reinen Schönheit offen.

Die Monatsschrift „Gottesminne“, ausschließlich der religiösen Dichtkunst zubestimmt und von dem Benediktinerpater Ansgar Pöllmann herausgegeben, erschien mit ihrem ersten Heft ein dreiviertel Jahr vor dem ersten Heft des „Hochland“, war aber schon eine der Reaktionen auf Muths Reformideen und nahm darüber hinaus Anregungen des Ausstattungskultus der „,neuen Buchkunst“" auf. Die hier wiedergegebene These des dänischen Schriftstellers JoHANnES JörGENSEN (1866-1956), Dozent an der katholischen Universität Löwen, hält verklausuliert die strikte Gegenposition zu Muth fest, auch darin, daß sie Kunst umstandslos in den Rahmen der Darstellung von Tugend und Sünde auf Grund göttlicher Erleuchtung hineinstellt. 